Original article

\title{
Translation and validation of an ageism scale for dental students in Switzerland
}

\author{
Eleni Michalopoulou ${ }^{1)}$, Michael M. Bornstein ${ }^{2}$, Martin Schimmel ${ }^{3,4)}$, Anastassia Kossioni ${ }^{5}$, Nicole Kalberer ${ }^{1)}$, \\ Leonardo Marchini'), and Murali Srinivasan ${ }^{1)}$
}

${ }^{1)}$ Clinic of General, Special Care and Geriatric Dentistry, Center of Dental Medicine, University of Zurich, Zurich, Switzerland

${ }^{2}$ Department of Oral Health \& Medicine, University Center for Dental Medicine Basel UZB, University of Basel, Basel, Switzerland

${ }^{3)}$ Department of Reconstructive Dentistry and Gerodontology, School of Dental Medicine, University of Bern, Bern, Switzerland

4) Division of Gerodontology and Removable Prosthodontics, University Clinics of Dental Medicine, University of Geneva, Geneva Switzerland

${ }^{5)}$ Division of Gerodontology, Department of Prosthodontics, Dental School, National and Kapodistrian University of Athens, Athens, Greece

${ }^{6}$ Department of Preventive and Community Dentistry, The University of Iowa College of Dentistry and Dental Clinics, Iowa, IA, USA

\begin{abstract}
Purpose: This study aimed to validate an ageism scale for dental students in Switzerland.

Methods: The original scale was first translated to German and then evaluated by 14 experts for relevance; four items were eliminated. Validation of the resulting questionnaire was performed at three Swiss dental schools. Principal component analysis (PCA) was performed; Cronbach's alpha $(\alpha)$ was used to assess the internal consistency reliability, and Pearson's coefficient to identify any correlations with demographic parameters $(P<0.05)$. Results: PCA revealed 11 items among 4 factors (Overall: 11 items, $\alpha$ $=0.63$, variance $=56.6 \%$; Factor \#1 (F1): items $=3, \alpha=0.64 ;$ Factor \#2 (F2): items $=3, \alpha=0.42$; Factor \#3 (F3): items $=3, \alpha=0.35$; Factor \#4 $(\mathrm{F} 4)$ : items $=2, \alpha=0.37) . \mathrm{F} 1$ and F4 were correlated with clinical experience (F1: $P=0.042 ; \mathrm{F} 4: P=0.006)$ and participation in a gerodontology course (F1: $P=0.021 ; \mathrm{F} 4: P=0.004)$. F1 was correlated with experience of dealing with the elderly $(P=0.031)$, while residence locality was correlated with F3 $(P=0.047)$ and F4 $(P=0.043)$. F2 was correlated with the presence of elderly in the family $(P=0.047)$.
\end{abstract}

Conclusion: The translated dental ageism questionnaire for Switzerland resulted in an 11-item scale with acceptable reliability.

Keywords: ageism scale, dental education, dental student, geriatric dentistry, gerodontology

\section{Introduction}

Population demographics have revealed that approximately 1.61 million people over the age of 65 years are living in Switzerland, of whom 453,000 are over 80 years of age. Based on the current trend, these numbers are likely to double by 2050 [Switzerland's population in 2019. In: Krummenacher A, Rausa F (eds). Swiss Statistics. Neuchâtel, 2020]. Due to their complex health histories and varying cognitive status, older adults often need multifaceted skills in all aspects of care from their healthcare professionals. Similarly, healthcare professionals also need appropriate attitudes and motivation whilst providing healthcare to this frail and vulnerable population. Social surveys conducted in Europe have suggested that older adults over 70 years of age are looked down upon by the majority of the younger/working segment, which consider that older adults do not contribute much to society and are a burden to the healthcare system [Abrams De et al. Ageism in Europe. Findings from the European Social Survey, Technical report AgeUK, 2011]. Negative attitudes towards older adults by the general population along with age-associated discrimination seem to be common in Europe [Abrams D et al. Ageism in Europe. Findings from the European Social Survey, Technical report AgeUK, 2011]. However, it is interesting to note that some reports have indicated that ageism is also

Correspondence to Dr. Murali Srinivasan, Clinic of General, Special Care and Geriatric Dentistry, Center of Dental Medicine, University of Zurich, Plattenstrasse 11, Zurich 8032, Switzerland

Email: murali.srinivasan@zzm.uzh.ch

doi.org/10.2334/josnusd.21-0389

DN/JST.JSTAGE/josnusd/21-0389 present among healthcare professionals [1-6]. Ageism, even in its subtlest form, can affect healthcare provision to older adults and may influence the treatment options proposed, or even present a risk of not being offered, to older adults $[3,4]$. Therefore, it is important for all healthcare professionals and caregivers to show a positive attitude towards older adults.

Ageism can be assessed using different instruments (scales) that measure the attitudes towards older adults by colleagues in the workplace, by healthcare professionals and/or by medical students [1,7-14]. Assessment of ageist attitudes is important, as it can estimate the presence of ageism, and help develop training programs fostering better attitudes, or cultivating a positive mindset towards older adults to overcome this stereotypic barrier [15]. Although studies in dentistry have been conducted to assess the attitude of dentists/dental hygienists towards treating older adults, they employed instruments that were not specifically designed for dental medicine [16-18]. Whether these instruments can successfully detect ageist attitudes among dental students has not been verified.

Recently, a 27-item ageism scale questionnaire specifically designed to assess ageism among dental students (ASDS) has been developed by American and European gerodontology educators $[19,20]$ and validated successfully for different cultures [21-23]. The aim of the present study was to translate and validate the existing ASDS in German for dental students in the German-speaking part of Switzerland.

\section{Materials and Methods}

\section{Survey questionnaire}

The original ASDS questionnaire included a demographic section (10 items) and an ageism scale (27 items). Each of the items on the ageism scale evoked a 6-point Likert scale-type response (1 strongly disagree, 2 disagree, 3 slightly disagree, 4 slightly agree, 5 agree, 6 strongly agree). Scores for 9 negatively phrased items in the ASDS need to be reversed (Q5, Q6, Q7, Q9, Q15, Q21, Q22, Q24, Q26) before being added to the total score and analysis. The demographic part (comprising 10 items) collected information about the participants' dental school, gender, age, ethnic background, semester of study, clinical experience, participation in a gerodontology course, presence of older adults in their families, experience of living with older adults, and the residential area participants live in.

Translation of the questionnaire and content validity analysis (CVA) The 27-item ASDS questionnaire was translated into German for Switzerland in accordance with the Medical Outcomes Trust criteria (1997) [http:// www.outcomes-trust.org/bulletin/0797blltn.htm]. The questionnaire was translated from English to German, and then back-translated from German to English by two bilingual translators. The questionnaires were reviewed and checked for any problems in comprehension. If any such problems existed, appropriate corrections were made accordingly including reassessments.

The translated (German-version) questionnaire was then sent to a panel of special care and geriatric dentistry experts. The relevance of all the items as well as the demographic parameters was scored binomially (necessary or not necessary) by the panel of experts, and a content validity ratio (CVR) was calculated. The CVR was calculated using the formula: 
Table 1 Demographic information for the panel of experts

\begin{tabular}{|c|c|c|}
\hline & Expert panel A (all) & Expert panel B (experienced) \\
\hline Total $(n)$ & 14 & 7 \\
\hline Women $(n[\%])$ & 6 & 3 \\
\hline $\operatorname{Men}(n[\%])$ & 8 & 4 \\
\hline Age (mean $\pm \mathrm{SD}$ ) in years & $37.7 \pm 9.1$ & $39.6 \pm 7.6$ \\
\hline $\begin{array}{l}\text { Experience in dentistry in years } \\
\text { (mean } \pm \mathrm{SD} \text {; range: min, max) }\end{array}$ & $\begin{array}{c}9.0 \pm 8.9 ; \\
\min =1.6, \max =29.9\end{array}$ & $\begin{array}{c}15.5 \pm 10.0 \\
\min =7.0, \max =29.9\end{array}$ \\
\hline $\begin{array}{l}\text { Experience as faculty member in Geriatric Dentistry in years } \\
(\text { mean } \pm \text { SD) }\end{array}$ & $\begin{aligned} & 4.9 \pm 4.3 \\
\min = & 2.7, \max =14.1\end{aligned}$ & $\begin{array}{c}7.4 \pm 4.7 \\
\min =2.7, \max =14.1\end{array}$ \\
\hline
\end{tabular}

Table 2 Content validity analysis of the proposed questionnaire items by the expert panel

\begin{tabular}{|c|c|c|}
\hline Demographic Items & $\mathrm{CVR}_{\mathrm{a}}$ & $\mathrm{CVR}_{\mathrm{b}}$ \\
\hline D1: Dental school* & 0.4 & 0.4 \\
\hline D2: Sex (M/F) & $0.9^{f}$ & $1.0^{i}$ \\
\hline D3: Age & $0.9^{f}$ & $1.0^{i}$ \\
\hline D4: Semester of studies (study year) & $0.6^{f}$ & 0.7 \\
\hline D5: Race* & 0.0 & 0.1 \\
\hline D6: Months of clinical experience & $0.7^{f}$ & $1.0^{\mathrm{i}}$ \\
\hline D7: Attendance at a gerodontology course $(\mathrm{Y} / \mathrm{N})$ & $0.9^{f}$ & $1.0^{\mathrm{i}}$ \\
\hline D8: Are there older people in your family? $(\mathrm{Y} / \mathrm{N})$ & $0.9^{f}$ & $1.0^{i}$ \\
\hline D9: Do you live (or have lived) with elderly people? (Y/N) & $0.9^{f}$ & $1.0^{\circ}$ \\
\hline D10: Is your permanent home address (your parents' address) in an urban or in a rural area? (urban/rural) & $0.6^{f}$ & 0.7 \\
\hline \multicolumn{3}{|l|}{ Ageism questionnaire items } \\
\hline Q1: Research funding should be mainly allocated to the treatment of pediatric issues instead of geriatric ones. & $0.6^{f}$ & 0.7 \\
\hline Q2: Taking a medical history from elderly patients is frequently time-consuming. & $0.9^{f}$ & 0.7 \\
\hline Q3: Taking a medical history from elderly patients is frequently complex. & $0.9^{f}$ & 0.7 \\
\hline Q4: I would rather treat elderly patients than younger dental patients. & $0.6^{f}$ & $1.0^{\mathrm{i}}$ \\
\hline Q5: I tend to pay more attention toward my elderly patients than my younger patients. & 0.4 & $1.0^{\circ}$ \\
\hline Q6: I tend to have more sympathy toward my elderly patients than towards my younger patients.* & 0.4 & 0.7 \\
\hline Q7: In general, elderly people contribute a lot to society. & $0.9^{f}$ & 1.0 \\
\hline Q8: Elderly patients are better off in nursing homes. * & 0.3 & 0.1 \\
\hline Q9: Elderly patients tend to be more appreciative of the dental care I provide than do younger patients. & $0.7^{f}$ & 0.7 \\
\hline Q10: Elderly patients often will not accept recommended treatment plans. & $0.7^{f}$ & 0.7 \\
\hline Q11: Elderly patients have fixed ideas about what is proper dental treatment. & $0.6^{f}$ & 0.7 \\
\hline Q12: My dental treatment planning for elderly patients is consistent with that for my middle-aged patients. & $0.7^{f}$ & 0.7 \\
\hline Q13: Elderly people do not take good care of their teeth. & $0.7^{f}$ & $1.0^{\mathrm{i}}$ \\
\hline Q14: Elderly patients do not usually comply with dental advice. & $0.6^{f}$ & 0.4 \\
\hline Q15: It is government's responsibility to provide dental care for elderly people. & $0.7^{f}$ & $1.0^{i}$ \\
\hline Q16: Elderly patients do not live long enough to make it worthwhile to invest time and effort in complex dental treatment. & $0.7^{f}$ & 0.7 \\
\hline Q17: Elderly patients do not live long enough to make it worthwhile to invest money in expensive dental treatment. & $0.6^{f}$ & 0.4 \\
\hline Q18: Dental treatment of elderly patients is often too time-consuming. & $0.7^{f}$ & 0.7 \\
\hline Q19: It is too costly to provide out of office dental care to homebound elderly patients. & $0.6^{f}$ & 0.7 \\
\hline Q20: Cost is a major barrier to many elderly patients seeking dental care. & $0.7^{f}$ & 0.7 \\
\hline Q21: Dental treatment is usually successful in elderly patients.* & 0.4 & 0.4 \\
\hline Q22: My exposure to geriatric dentistry has been adequate. & $0.7^{f}$ & 0.7 \\
\hline Q23: It is normal for elderly people to have oral problems. & $0.7^{f}$ & 0.7 \\
\hline Q24: I would provide more homecare or nursing home dental treatment if I had more training. & $0.6^{f}$ & 0.4 \\
\hline Q25: Elderly patients should be treated by someone with advanced training in geriatric dentistry. & $1.0^{f}$ & $1.0^{i}$ \\
\hline Q26: I feel comfortable treating someone with a long medication list. & $0.7^{f}$ & 0.7 \\
\hline Q27: I tend to favor extractions over extensive restorative procedures when planning treatment for elderly patients.* & 0.4 & 0.1 \\
\hline
\end{tabular}

$\mathrm{CVR}$, content validity ratio (calculated using the formula $\mathrm{CVR}=\frac{n_{\mathrm{e}}-\frac{N}{2}}{\frac{N}{2}}$, where $n_{\mathrm{e}}$ is the number of the experts who rate an item as necessary and, $N$ is the total number of participating experts); 'qualifies for inclusion by criteria CVR $>0.99$; ${ }^{f}$ qualifies for inclusion by criteria CVR $>0.51$; a, entire panel of experts; b, experts employed as faculty members in a dedicated geriatric dental clinic more than 5 years; *deleted as they did not qualify in both the expert categories (a and b).

$\mathrm{CVR}=\frac{n_{e}-\frac{N}{2}}{\frac{N}{2}}$

where ' $n_{\mathrm{e}}$ ' is the number of experts who rate an item as necessary and, ' $N$ ' is the total number of participating experts. The CVR determines whether the item remains in the questionnaire and the cut-off value of the CVR differs according to the number of participating experts. This study had 14 experts in the panel and 7 of them were well experienced. Two CVRs were calculated for each item: an overall CVR $\left(\mathrm{CVR}_{\mathrm{a}}\right)$ including 14 experts, and a second CVR $\left(\mathrm{CVR}_{\mathrm{b}}\right)$ including seven very experienced experts (minimum 5 years of experience in a geriatric clinic). Demographic information for the expert panel is shown in Table 1. An item was excluded from the questionnaire if it failed to satisfy the minimum required value in both CVR categories, i.e., when the values fell below 0.51 and 0.99 for $\mathrm{CVR}_{\mathrm{a}}$ and $\mathrm{CVR}_{\mathrm{b}}$, respectively. Two demographic items (dental school and race), and four questions (Q6, Q8, Q21 and Q27) from the original ASDS scale were excluded after the CVA (Table 2). The final Swiss-German version (ASDS_DE) had 8 items in the demographic section, and 23 items in the ageism scale.

This questionnaire was pilot tested with 15 students to check for difficulties in comprehension, completability, time factors, and any other problems that may exist. Problems were identified, corrected, and reassessed. The finalized ASDS_DE questionnaire (Table 3) along with a brief project summary were then sent to the relevant ethics committee and clarification of responsibility was sought before beginning the validation. The relevant ethics committee in Zurich (Kantonale Ethikkommission Zurich [KEK-Zurich]) judged that this project did not fall within the scope of the Human Research Act (HRA), and therefore did not require authorization from the ethics committee (Baseq-Nr. Req-2020-00689). 
Table 3 Twenty-three items validated by the Swiss panel of experts for the preliminary version of the dental students' ageism scale

1. Research funding should be allocated mainly to the treatment of pediatric rather than geriatric issues.

2. Taking a medical history from elderly patients is frequently time-consuming.

3. Taking a medical history from elderly patients is frequently complex.

4. I would rather treat elderly patients than younger dental patients.

5. *I tend to pay more attention to my elderly patients than to my younger patients.

6. *In general, elderly people contribute a lot to society.

7. *Elderly patients tend to be more appreciative of the dental care I provide than do younger patients.

8. Elderly patients often will not accept recommended treatment plans.

9. Elderly patients have fixed ideas about what is proper dental treatment

10. My dental treatment planning for elderly patients is consistent with that for my middle-aged patients.

11. Elderly people do not take good care of their teeth.

12. Elderly patients do not usually comply with dental advice.

13. *It is government's responsibility to provide dental care for elderly people.

14. Elderly patients do not live long enough to make it worthwhile to invest time and effort in complex dental treatment.

15. Elderly patients do not live long enough to make it worthwhile to invest money in expensive dental treatment.

16. Dental treatment of elderly patients is often too time-consuming.

17. It is too costly to provide out of office dental care to homebound elderly patients.

18. Cost is a major barrier to many elderly patients seeking dental care.

19. *My exposure to geriatric dentistry has been adequate.

20. It is normal for elderly people to have oral problems.

21. *I would provide more homecare or nursing home dental treatment if I had more training.

22. Elderly patients should be treated by someone with advanced training in geriatric dentistry

23. *I feel comfortable treating someone with a long medication list.

*negatively worded questions requiring the scores to be reversed

Table 4 Participant demographics

\begin{tabular}{|c|c|c|c|c|}
\hline & Zurich & Basel & Bern & Total / Overall \\
\hline Number of participating students $(n[\%])$ & $104(74.3)$ & $21(15.0)$ & $15(10.7)$ & $140(100.0)$ \\
\hline Response rate $(\%)$ & $104 / 120(86.6)$ & $21 / 21(100.0)$ & $15 / 30(50.0)$ & $140 / 171(81.9)$ \\
\hline \multicolumn{5}{|l|}{$\operatorname{Sex}(n[\%])$} \\
\hline Women & $60(57.7)$ & $13(61.9)$ & $9(60.0)$ & $82(58.6)$ \\
\hline Men & $42(40.4)$ & $8(38.1)$ & $6(40.0)$ & $56(40.0)$ \\
\hline Did not respond & $2(1.9)$ & - & - & $2(1.4)$ \\
\hline Age (mean $\pm \mathrm{SD})$ & $25.2 \pm 2.2$ & $26.5 \pm 3.2$ & $25.9 \pm 3.3$ & $25.5 \pm 2.5$ \\
\hline Clinical experience in months (mean \pm SD) & $3.3 \pm 1.7$ & $4.0 \pm 0.6$ & $4.4 \pm 0.8$ & $3.5 \pm 1.5$ \\
\hline \multicolumn{5}{|l|}{ Attendance at a gerodontology course } \\
\hline Yes & $82(78.8)$ & $21(100.0)$ & $15(100.0)$ & $118(84.3)$ \\
\hline No & $21(20.2)$ & - & & $21(15.0)$ \\
\hline Did not respond & $1(1.0)$ & - & & $1(0.7)$ \\
\hline \multicolumn{5}{|l|}{ Older people in the family ( $n[\%]$ ) } \\
\hline Yes & $92(88.5)$ & $20(95.2)$ & $14(93.3)$ & $126(90.0)$ \\
\hline No & $11(10.6)$ & $1(4.8)$ & $1(6.7)$ & $13(9.3)$ \\
\hline Did not respond & $1(1.0)$ & - & - & $1(0.7)$ \\
\hline \multicolumn{5}{|l|}{ Experience of living with elderly ( $n[\%]$ ) } \\
\hline Yes & $24(23.1)$ & $7(33.3)$ & $7(46.7)$ & $38(27.1)$ \\
\hline No & $79(76.0)$ & $14(66.7)$ & $8(53.3)$ & $101(72.1)$ \\
\hline Did not respond & $1(1.0)$ & - & - & $1(0.7)$ \\
\hline \multicolumn{5}{|l|}{ Locality of residence $(n[\%])$} \\
\hline Urban (City) & $58(55.8)$ & $8(38.1)$ & $4(26.7)$ & $70(50.0)$ \\
\hline Rural (Suburbs) & $44(42.3)$ & $13(61.9)$ & $10(66.7)$ & $67(47.9)$ \\
\hline Did not respond & $2(1.9)$ & - & $1(6.7)$ & $3(2.1)$ \\
\hline
\end{tabular}

\section{Participants}

The participants included in this study were dental students in their final year from the Swiss universities of Zurich, Basel and Bern. In Zurich and Basel, the printed questionnaires were handed to the students and the responses were collected by hand. In Bern, due to the coronavirus disease of 2019 (COVID-19) pandemic, the questionnaires were administered and collected electronically. The completed questionnaires were then anonymized for further evaluation. Participation in the survey was voluntary and willingness to complete the questionnaire indicated consent.

\section{Statistical analysis}

Means and standard deviations were calculated, and the data were verified for a Gaussian distribution. Principal components analysis (PCA) was performed to explore the internal structure of measures using varimax rotation. The Kaiser-Meyer-Olkin (KMO) test was used to measure the sampling adequacy. A KMO of 0.8 or more and 0.6 or less was considered ideal and inadequate, respectively. Bartlett's test of sphericity was performed to check the factorability of the sample. Factors with eigenvalues of 1.0 or greater were extracted. Items with a loading below 0.4 or above
0.8, along with those items loading on multiple factors were removed. The process was repeated until a parsimonious solution was achieved. Cronbach's alpha $(\alpha)$ was calculated to check the internal consistency reliability. Correlations between the demographic parameters and the items or factors were assessed using Pearson's correlation coefficient $(\alpha=0.05)$. All statistical tests were performed using a statistical software package (version 25.0, SPSS Statistics, IBM Corp., Armonk, NY, USA).

\section{Results}

A total of 140 students from three dental schools in Switzerland participated in this validation study with an overall response rate of $81.9 \%$ (Table 4). After five rounds of PCA and elimination of poorly and cross-loading factors, 11 items distributed into four factors (KMO: $0.7 ; P<0.001$, Bartlett's test) were revealed, accounting for $56.6 \%$ of the overall variance (Table 5). The Cronbach's $\alpha$ for these 11 items was 0.63 , which can be considered acceptable.

Pearson's coefficient revealed a negative correlation between factor 1 (patient compliance), clinical experience $(r=-0.17, n=138, P=0.042)$, 
Table 5 Principal component analysis (PCA) for the final 11 items categorized into 4 factors

\begin{tabular}{|c|c|c|}
\hline Overall Cronbach's alpha $(\alpha)=0.63$ (final 11 items) & Factor loading & Mean \pm SD \\
\hline \multicolumn{3}{|l|}{ Factor $1(\alpha=0.64)$ : Patient compliance } \\
\hline Q8: Elderly patients often will not accept recommended treatment plans & 0.7 & $2.8 \pm 0.9$ \\
\hline Q9: Elderly patients have fixed ideas about what is proper dental treatment & 0.7 & $3.0 \pm 0.9$ \\
\hline Q22: Elderly patients should be treated by someone with advanced training in geriatric dentistry & 0.7 & $4.0 \pm 0.9$ \\
\hline \multicolumn{3}{|l|}{ Factor $2(\alpha=0.42)$ : Opinions about elderly } \\
\hline Q6: *In general, elderly people contribute a lot to society & 0.7 & $2.9 \pm 1.0$ \\
\hline Q18: Cost is a major barrier to many elderly patients seeking dental care & 0.7 & $3.4 \pm 1.1$ \\
\hline Q12: Elderly patients do not usually comply with dental advice & 0.6 & $2.5 \pm 0.8$ \\
\hline \multicolumn{3}{|l|}{ Factor $3(\alpha=0.35)$ : Barriers / concerns on dental treatment for the elderly } \\
\hline Q21: *I would provide more homecare or nursing home dental treatment if I had more training & 0.7 & $3.5 \pm 1.0$ \\
\hline Q16: Dental treatment of elderly patients is often too time-consuming & 0.5 & $2.4 \pm 1.0$ \\
\hline Q1: Research funding should be allocated mainly to the treatment of pediatric rather than geriatric issues & 0.5 & $2.8 \pm 1.0$ \\
\hline \multicolumn{3}{|l|}{ Factor $4(\alpha=0.37)$ : Practitioners' perspective } \\
\hline Q19: * My exposure to geriatric dentistry has been adequate & 0.7 & $3.0 \pm 1.1$ \\
\hline Q7: *Elderly patients tend to be more appreciative of the dental care I provide than do younger patients & 0.7 & $3.2 \pm 1.0$ \\
\hline
\end{tabular}

Q7: *Elderly patients tend to be more appreciative of the dental care I provide than do younger patien $\alpha$, Cronbach's alpha; *scores reversed; SD, standard deviation; Rotation method: Varimax with Kaiser normalization

Table 6 Correlation of various demographic parameters with the 11 items of the components

\begin{tabular}{|c|c|c|c|c|c|c|c|}
\hline \multirow[b]{2}{*}{ Factor and items in each factor } & \multicolumn{7}{|c|}{$P$ - value (bivariate correlation) } \\
\hline & Sex & Age & $\begin{array}{l}\text { Clinical } \\
\text { experience }\end{array}$ & $\begin{array}{l}\text { Participation in } \\
\text { a gerodontology } \\
\text { course }\end{array}$ & $\begin{array}{l}\text { Elderly in } \\
\text { family }\end{array}$ & $\begin{array}{l}\text { Living with } \\
\text { elderly } \\
\text { experience }\end{array}$ & $\begin{array}{c}\text { Residence } \\
\text { location }\end{array}$ \\
\hline Factor 1: Patient compliance & 0.895 & 0.233 & 0.042 & 0.021 & 0.418 & 0.031 & 0.246 \\
\hline Q8: Elderly patients often will not accept recommended treatment plans & 0.517 & 0.887 & 0.014 & 0.014 & 0.680 & 0.015 & 0.183 \\
\hline Q9: Elderly patients have fixed ideas about what is proper dental treatment & 0.730 & 0.760 & 0.613 & 0.085 & 0.676 & 0.011 & 0.855 \\
\hline Q22: Elderly patients should be treated by someone with advanced training in geriatric dentistry & 0.684 & 0.135 & 0.117 & 0.066 & 0.835 & 0.416 & 0.915 \\
\hline Factor 2: Opinions about elderly & 0.695 & 0.451 & 0.825 & 0.388 & 0.047 & 0.105 & 0.864 \\
\hline Q6: *In general, elderly people contribute a lot to society & 0.558 & 0.448 & 0.971 & 0.448 & 0.062 & 0.458 & 0.625 \\
\hline Q12: Elderly patients do not usually comply with dental advice & 0.288 & 0.773 & 0.337 & 0.089 & 0.438 & 0.468 & 0.409 \\
\hline Q18: Cost is a major barrier to many elderly patients seeking dental care & 0.351 & 0.727 & 0.975 & 0.266 & 0.645 & 0.311 & 0.503 \\
\hline Factor 3: Barriers / concerns on dental treatment in elderly & 0.183 & 0.180 & 0.626 & 0.942 & 0.914 & 0.542 & 0.047 \\
\hline Q1: Research funding should be allocated mainly to the treatment of pediatric rather than geriatric issues & 0.150 & 0.263 & 0.407 & 0.573 & 0.594 & 0.020 & 0.061 \\
\hline Q16: Dental treatment of elderly patients is often too time-consuming & 0.655 & 0.989 & 0.726 & 0.739 & 0.957 & 0.657 & 0.118 \\
\hline Q21: *I would provide more homecare or nursing home dental treatment if I had more training & 0.671 & 0.117 & 0.318 & 0.544 & 0.404 & 0.314 & 0.546 \\
\hline Factor 4: Practitioner's perspective & 0.285 & 0.414 & 0.006 & 0.004 & 0.867 & 0.649 & 0.043 \\
\hline Q7: *Elderly patients tend to be more appreciative of the dental care I provide than do younger patients & 0.138 & 0.017 & 0.777 & 0.072 & 0.491 & 0.539 & 0.097 \\
\hline Q19: *My exposure to geriatric dentistry has been adequate & 0.684 & 0.188 & $<0.001$ & 0.004 & 0.459 & 0.924 & 0.052 \\
\hline
\end{tabular}
Q19: *My exposure to geriatric dentistry has been adequate

and experience of living with older adults $(r=-0.18, n=139, P=0.031)$, but a positive correlation with participation in a gerodontology course $(r$ $=0.20, n=139, P=0.021$ ). Factor 2 (opinions about older adults) was negatively correlated with the presence of older adults in the family $(r=$ $-0.17, n=139, P=0.047$ ). Factor 3 (barriers or concerns related to dental treatment for older adults) was positively correlated with the locality (city or rural) of the participant's residence $(r=0.17, n=137, P=0.047)$. Factor 4 (practitioner's perspective) was negatively correlated with clinical experience $(r=-0.23, n=138, P=0.006)$ and the locality of the participant's residence $(r=-0.17, n=137, P=0.043)$, but positively correlated with participation in a gerodontology course $(r=0.25, n=139, P=0.004)$.

Individual items that showed significant correlations with the demographic parameters were Q7 with age $(r=0.20, n=136, P=0.017)$. Q19 was influenced by clinical experience $(r=-0.35, n=137, P<0.001)$ and participation in a gerodontology course $(r=0.25, n=138, P=0.004)$. Experience of living with older adults was correlated with Q8 $(r=-0.21$, $n=138, P=0.015)$; Q9 $(r=-0.22, n=139, P=0.011)$; Q1 $(r=-0.12, n$ $=137, P=0.020$ ). There was no significant difference among the components for sex and age. All correlations between demographic parameters and the factors or items are shown in Table 6.

\section{Discussion}

The translated ageism dental scale, which was validated for the German language as used by German-speaking participants resident in Switzerland, produced an 11-item questionnaire distributed into four components (1. patient compliance, 2. opinions about older adults, 3. barriers and con- cerns regarding dental treatment for older adults, and 4. practitioners' perspective). "Patient compliance" (factor 1) comprised 3 items. Two of the three items in this factor (Q8 "Elderly patients often will not accept recommended treatment plants" and Q9 "Elderly patients have fixed ideas about what is proper dental treatment") were also identified in the Greek version of the ageism scale for dental students under the same category of "compliance" [21]. Q8 was also present in the Brazilian version but under the category of "negative view of older patients" [22]. The third item in this paper, Q22 "Elderly patients should be treated by someone with advanced training in geriatric dentistry", was identified in the Greek version as well, but categorized under "Barriers" [21]. Factor 1 was correlated to three demographic parameters: clinical experience, experience with the elderly, and participation in a gerodontology course. It was negatively influenced by clinical experience, and also by experience of living with older adults. It is understandable that participants with less clinical experience would have higher scores. This can be attributed to the lack of clinical experience in patient handling per se, which would become more evident when dealing with older adults with complex medical and cognitive statuses. This highlights the importance of gerodontology training at the undergraduate level. Adequate training and exposure might be an apt solution for improving performance whilst managing complex, noncompliant patients. It is interesting to observe that even if participants had experience of living with older adults, the scores were still high. This is probably because living with older adults generates a true opinion about their compliance, as the participants would have had first-hand experience of issues determining whether or not older adults would cooperate. This is not necessarily a negative reflection of attitudes, but perhaps a result of true experience. 
The results revealed that the scores for "patient compliance" were better if participants had already taken courses in gerodontology. This further strengthens the belief in the importance of a well-structured and complete gerodontology curriculum for undergraduate dental students.

"Opinions about older adults" (factor 2) in this questionnaire comprised a set of three items: Q6 "In general, elderly people contribute a lot to society", Q8 "Cost is a major barrier to many elderly patients seeking dental care", and Q12 "Elderly patients do not usually comply with dental advice". Q6 had been identified in the Romanian and the Greek versions of the ASDS under "perceptions about older persons" and "value/ethics about older people", respectively [21,23]. Q18 and Q12 of the questionnaire are also present in the Greek version, but under "barriers" and "compliance", respectively [21]. This factor was correlated with a single demographic parameter - the presence of older adults in the family - which elicited a lower ageism score. This represents a factor that is crucial for developing favorable emotional attitudes towards older adults and in reducing stereotyping. This cultivates positivity towards older adults in general from the early formative years, which is retained throughout life. Studies have demonstrated that grandparent-grandchild interactions are compassionate and emotionally close [24]. Grandparents or other older adults present in the family often act as custodial caregivers for their grandchildren. This ensures exposure of the child to an older adult at a young age, in most cases for a considerable length of time. Evidence suggests that most grandparentgrandchild relationships are considered significant, meaningful, close and enduring [25]. These interactions have an influential effect on a child's emotional well-being and foster a caring and empathetic attitude towards older adults [26]. This effect has been evidenced by published studies that demonstrate a more positive attitude towards older adults in undergraduate students when they have been exposed to geriatric patients $[4,6,18]$.

In the "Barriers/concerns" (factor 3) category, the analysis included three items (Q21, Q16 and Q1); Q16 "Dental treatment of elderly patients is often too time-consuming" was also identified by the US version of the ageism scale [19]. Factor 3 was correlated with only one demographic parameter (location of residence). The scores were higher for participants living in rural areas. Limited access quality dental care is quite common for institutionalized or compromised older adults in rural areas. This can be due to a number of reasons including lack of resources, lack of healthcare professionals with appropriate training, experience, and motivation, as well as economic factors. The last factor (factor 4) identified had two items relating to "practitioners' perspective", Q19 "My exposure to geriatric dentistry has been adequate" and Q7 "Elderly patients tend to be more appreciative of the dental care I provide than younger patients". Q19 and Q7 were identified in the Romanian version ("dental students' exposure") and Greek version (“dentist-older patient interactions"), respectively.

This translation and validation of the ageism scale for dental students, developed by Rucker et al. (2018) [19], is the first such attempt in a Swiss context. When comparing the Swiss version with the original ageism scale (ASDS) [19], both the Swiss and American scales had no significant correlations with the sex of the participants. On the other hand, the Greek version revealed statistically significant differences for items related to participant gender. The Swiss sample showed slight difference depending on the year of study and participation in a gerodontology course. These differences were small and should be interpreted carefully since this preliminary analysis was limited in size and aimed at providing initial guidance for a future study in a larger sample. Furthermore, students mostly from Zurich and fewer from the other Swiss universities participated in this survey and therefore final conclusions for the instrument's validity in Switzerland should be drawn after validation in a larger sample. The preliminary results are encouraging, and perhaps another French-version validation is required for the Swiss-French regions of Switzerland. The panel of experts eliminated four items (Q6, Q8, Q21, Q27) at the beginning from the original ASDS scale, along with two demographic questions (Swiss Dental School, Race). These items were eliminated as a consequence of the content validity analysis performed with the panel of experts. Although the binomial assessment of the items might not be considered the most objective method on scientific grounds, it may nevertheless be considered robust as this type of assessment is used frequently in other studies with similar foci. However, this may be considered a limitation of the present study as it led to elimination of certain items that were considered useful in the other translated and validated versions of the ASDS questionnaire.
The elimination of these 4 items (Q6, Q8, Q21, Q27) from the original ASDS scale along with two demographic questions (Swiss Dental School, Race) might have influenced the component categorizations. However, it must be considered that each individual society is diverse geographically, culturally, socially and economically. Switzerland is also a diverse country with a cosmopolitan international population, especially in big cities such as Bern, Basel, Geneva and Zurich, where the dental schools and universities are located. It is a landlocked country sharing its immediate borders with many European countries (Germany, France, Austria, Italy and Lichtenstein). People living in these border regions work and commute to Switzerland on a daily basis. Most of them have families in Switzerland who are educated in Switzerland. Education in Switzerland is free to all who reside or possess a work permit for Switzerland. Moreover, Geneva, Zurich, Bern and Basel are home to multinational corporations and the United Nations. Employees of these corporations live for many years and eventually settle down and obtain naturalization. This makes the Swiss population very diverse and includes individuals from all communities. Swiss universities follow the Bologna concept and the syllabi followed in medical and dental universities are standardized. After completion of their medical and dental studies, students are required to undergo a centralized federal examination, which is common to all. Therefore, it would be safe to assume that the level and content of education received in Switzerland would be standardized. Hence, from a societal and educational viewpoint, elimination of the items deemed unnecessary by the panel of experts would have been justified as they were not relevant to the Swiss context. Another limiting factor might have been the Covid-19 pandemic, which made it necessary to conduct the survey partly over digital channels. This might have affected the response rates for the participating centers, or the responses may have been positively influenced by students who were particularly interested in the topic of ageism. However, all steps were taken to ensure that participant numbers were maximized at each participating center. Nevertheless, although this validation was performed at three of the four university dental schools in Switzerland, all were located in the Swiss-German speaking regions, and therefore the validation may not be considered to represent the nation as a whole, as validations for the French and Italian parts of Switzerland were not performed. These validations will need to be performed in a future study. Furthermore, it is also important to bear in mind that although the ASDS German version for Switzerland was performed at three Swiss dental schools in the Swiss-German regions of Switzerland and the results for each item were interesting, they cannot be compared with previously reported studies because currently there are no comparable data. Consequently, this aspect must also be considered a limitation of the current validation and study. Further studies employing the currently validated questionnaire must be conducted in purpose-built surveys to generate data for comparison with future validation studies.

The translated German version of the dental ageism scale (ASDS_DE) for Switzerland resulted in a four-component, 11-item scale with acceptable reliability. These results warrant further investigation in an expanded multi-institutional, proportionally equal Swiss sample.

\section{Acknowledgments}

The authors would like to thank all the dental students, as well as the panel of experts, who participated in this study, and Mr. Patrick Barlow for his advice on the statistical analysis. The authors extend their gratitude to Ms. Elena van der Heijden from the University of Zurich, Ms. Christl Hösch from the University of Basel, and Ms. Benedicta Gruber from the University of Bern for their gracious support with the execution of this study. This study received no external funding.

\section{Conflicts of interest}

None.

\section{References}

1. Kogan N (1961) Attitudes toward old people: the development of a scale and an examination of correlates. J Abnorm Soc Psychol 62, 44-54.

2. Beck JD, Ettinger RL, Glenn RE, Paule CL, Holtzman JM (1979) Oral health status: impact on dental student attitudes toward the aged. Gerontologist 19, 580-584.

3. Bowling A (1999) Ageism in cardiology. BMJ 319, 1353-1355.

4. Robb C, Chen H, Haley WE (2002) Ageism in mental health and health care: a critical review. J Clin Geropsychol 8, 1-12.

5. De Visschere L, Van Der Putten GJ, de Baat C, Schols J, Vanobbergen J (2009) The impact 
of undergraduate geriatric dental education on the attitudes of recently graduated dentists towards institutionalised elderly people. Eur J Dent Educ 13, 154-161.

6. Nochajski TH, Waldrop DP, Davis EL, Fabiano JA, Goldberg LJ (2009) Factors that influence dental students' attitudes about older adults. J Dent Educ 73, 95-104.

7. Rosencranz HA, McNevin TE (1969) A factor analysis of attitudes toward the aged. Gerontologist 9, 55-59.

8. Maxwell AJ, Sullivan N (1980) Attitudes toward the geriatric patient among family practice residents. J Am Geriatr Soc 28, 341-345.

9. Intrieri RC, von Eye A, Kelly JA (1995) The aging semantic differential: a confirmatory factor analysis. Gerontologist 35, 616-621.

10. Reuben DB, Lee M, Davis JW Jr, Eslami MS, Osterweil DG, Melchiore S et al. (1998) Development and validation of a geriatrics attitudes scale for primary care residents. J Am Geriatr Soc 46, 1425-1430.

11. Baum EE, Nelson KM (2007) The effect of a 12-month longitudinal long-term care rotation on knowledge and attitudes of internal medicine residents about geriatrics. J Am Med Dir Assoc 8, 105-109.

12. Gonzales E, Tan J, Morrow-Howell N (2010) Assessment of the refined aging semantic differential: recommendations for enhancing validity. J Gerontol Soc Work 53, 304-318.

13. Samra R, Griffiths A, Cox T, Conroy S, Knight A (2013) Changes in medical student and doctor attitudes toward older adults after an intervention: a systematic review. J Am Geriatr Soc 61, 1188-1196.

14. Burbank PM, Burkholder GJ, Dugas J (2018) Development of the perspectives on caring for older patients scale: psychometric analyses. Appl Nurs Res 43, 98-104.

15. Burnes D, Sheppard C, Henderson CR Jr, Wassel M, Cope R, Barber C et al. (2019) Interventions to reduce ageism against older adults: a systematic review and meta-analysis. Am J Public Health 109, e1-e9.

16. Isobe A, Izumi M, Akifusa S (2019) Attitudes towards people with dementia: a crosssectional study comparing dental hygiene students with registered dental hygienists.
Gerodontology 36, 45-54

17. Carellis C, Kalberer N, Abou-Ayash S, Schimmel M, Wittneben JG, Zitzmann NU et al (2021) Attitudes of dental students towards treating elderly patients. Dental students' attitudes on geriatric patients. Swiss Dent J 131.

18. Grandjean ML, Morier C, Piccardi C, Srinivasan M (2021) Survey on the attitudes of dental hygiene students towards treating elderly patients. Int J Dent Hyg 19, 176-183.

19. Rucker R, Barlow PB, Hartshorn J, Kaufman L, Smith B, Kossioni A et al. (2018) Development and preliminary validation of an ageism scale for dental students. Spec Care Dentis $38,31-35$.

20. Rucker R, Barlow PB, Hartshorn J, Kaufman L, Smith B, Kossioni A et al. (2019) Dual institution validation of an ageism scale for dental students. Spec Care Dentist 39, 28-33.

21. Kossioni AE, Ioannidou K, Kalyva D, Marchini L, Hartshorn J, Kaufman L et al. (2019) Translation and validation of the Greek version of an ageism scale for dental students (ASDS Gr). Gerodontology 36, 251-257.

22. Rucker R, Barlow PB, Bertolini Fernandes Dos Santos M, Carrera Malhao E, Kossioni A, Marchini L (2020) Translation and preliminary validation of an ageism scale for dental students in Brazil (ASDS-Braz). Gerodontology 37, 87-92.

23. Veenstra L, Barlow P, Kossioni A, Popescu SM, Mercut V, Tuculina MJ et al. (2021) Translation and validation of the ageism scale for dental students in Romanian (ASDS-Rom). Eur J Dent Educ 25, 12-17.

24. Silverstein M, Giarrusso R (2010) Aging and family life: a decade review. J Marriage Fam 72, 1039-1058

25. Hodgson LG (1992) Adult grandchildren and their grandparents: the enduring bond. Int J Aging Hum Dev 34, 209-225.

26. Hatami B, Ahmady AE, Khoshnevisan MH, Lando HA (2014) Senior dental student's attitudes toward older adults and knowledge of geriatric dental care in the islamic republic of Iran. East Mediterr Health J 19 Suppl 3, S172-177. 